\title{
Agendamento intermidiático nas eleições 2012: relações entre redes sociais online e webjornais regionais em duas capitais brasileiras
}

\section{Carlos d'Andréa and Isabela Campanha Careta}

\section{Resumo}

0 artigo tem como objetivo discutir 0 agendamento intermidiático entre as redes sociais dos candidatos à prefeitura de Belo Horizonte e Vitória e a cobertura dos webjornais regionais Em.com.br e Gazeta Online nas eleições municipais de 2012. Iniciamos uma discussão sobre as origens e a evolução das reflexões e pesquisas sobre agendamento e, em seguida, voltamo-nos para suas especificidades nas campanhas eleitorais contemporâneas. Após uma observação sistemática das matérias publicadas pelos dois webjornais e das postagens dos perfis oficiais dos candidatos, apresentamos as principais tendências do agendamento intermidiático nas campanhas das duas capitais. Na análise, destacamos significativas diferenças: em Vitória nota-se um forte agendamento intermidiático entre as redes sociais e os webjornais, enquanto em Belo Horizonte destacase um alinhamento de ambos com a agenda de campanha dos dois principais candidatos.

\section{Palavras-chave}

Agendamento. Intermídia. Eleições. Webjornais. Redes sociais online

Carlos d'Andréa I carlosdand@gmail.com Doutor em Linguística Aplicada pela Universidade Federal da Minas Gerais (UFMG). Professor do Departamento de Comunicação da UFMG.

Isabela Campanha Careta I isabela.campanha@ufv.br Graduanda em Comunicação Social/Jornalismo pela Universidade Federal de Viçosa (UFV) e bolsista Probic/Fapemig.

\section{Introdução}

0 poder dos meios de comunicação em pautar os temas mais presentes e relevantes para discussão social é um tema frequente de estudos no campo da Comunicação e tem na teoria do agendamento um espaço privilegiado de discussão.

Considerando as profundas modificações no ecossistema midiático desde as primeiras pesquisas sobre agendamento, apropriamonos nesse trabalho da noção de "agendamento intermidiático" para compreender a cobertura jornalística de campanhas eleitorais. (McCOMBS, 2009) Mais especificamente, nosso objetivo neste artigo é discutir 0 agendamento intermidiático entre as redes sociais dos candidatos à prefeitura de Belo Horizonte e Vitória e a cobertura dos webjornais regionais Em.com.br e Gazeta Online nas eleições municipais de 2012.

Apresentamos a seguir uma discussão sobre agendamento a partir de um levantamento bibliográfico dos principais estudos na área até as novas perspectivas, que enfatizam seu caráter intermidiático no atual cenário midiático. 
Em seguida, destacamos 0 agendamento nas campanhas eleitorais, com ênfase nos impactos das redes sociais on-line no processo de complexificação do debate político-eleitoral na atualidade. Apresentamos depois o método de coleta de dados e sintetizamos as principais tendências identificadas após o acompanhamento sistemático das matérias publicadas pelos dois webjornais e pelos perfis oficiais dos candidatos nas duas capitais.

\section{Agendamento: uma revisão}

0 estudo inicial da hipótese da agenda setting foi desenvolvido pelos investigadores norte-americanos Maxwell E. McCombs e Donald L. Shaw no final da década de 1960. A pesquisa empírica pioneira foi realizada durante as eleições presidenciais norte-americanas de novembro de 1968 com 0 objetivo de verificar o poder de agendamento dos meios de comunicação e avaliar a capacidade destes em promover temas que eram objeto de debates e de interesse público. Nos resultados, os autores indicaram que "as provas deste estudo de que os eleitores tendem a partilhar a definição composta dos media acerca do que é importante sugerem fortemente a sua função de agendamento" (McCOMBS; SHAW, 2000, p. 57).

Clóvis de Barros Filho (2001, p. 169) conceitua agenda setting como "um tipo de efeito social da mídia. É a hipótese segundo o qual a mídia, pela seleção, disposição e incidência de suas notícias, vem determinar os temas sobre os quais o público falará e discutirá". Já Brum (2001) explica que "a essência da agenda setting procura identificar se os temas que são expostos na grande mídia tornam-se importantes para os receptores, assim como se são pautas das conversas diárias".

Na óptica da agenda setting, acredita-se que a seleção de notícias exista em razão das próprias características dos meios. 0s jornalistas e profissionais da comunicação atuam como gatekeepers da informação, escolhendo assim quais assuntos irão noticiar e quais não serão destacados, propiciando ao público uma hierarquização das notícias (McCOMBS; SPELLMAN; WEAVER, 2000). Nesse processo, as práticas institucionalizadas do jornalismo condicionam para uma similaridade no relato dos fatos e na seleção das notícias. A interconexão dos temas partilhados entre as agendas da mídia noticiosa se reproduz na dinâmica jornalística através de critérios de noticiabilidade, que, como explica Traquina (2000), são constituídos por um conjunto de valores-notícia. Conforme 0 autor, "um aspecto fundamental dessa cultura profissional é a partilha de valores quanto à importância ou ao interesse que uma ocorrência ou questão poderá ter" (TRAQUINA, 2000, p. 25).

\section{A hipótese da agenda setting converge} neste contexto organizacional de seleção e hieraquização das informações pelas mídias massivas de modo que as notícias são ordenadas e separadas pelo grau de impacto e relevância aferidos pelas redações jornalísticas. McCombs 
e Shaw (1992 apud TRAQUINA, 2000, p. 39) explicam que a seleção das questões que constituirão a agenda determina o poder do jornalismo: "a selecção dos tópicos para a agenda jornalística e a seleção de enquadramentos para as 'estórias' acerca desses tópicos definem poderosos papéis de agenda-setting e responsabilidades éticas terríveis". Além das fontes institucionais e oficiais, as grandes empresas jornalísticas impõem-se como importantes fontes de informação e agentes promotores do agendamento das outras mídias. A cobertura das agências noticiosas, por exemplo, "é em grande medida a pressão exercida pelo contexto normativo jornalístico que se deve à crescente homogeneidade nos conteúdos $\mathrm{e}$ enquadramentos observáveis na agenda dos media" (PEREIRA NETO, 2011, p. 253).

As evidências proeminentes da influência midiática na orientação pública e as significativas mudanças no sistema midiático marcam as transformações das pesquisas sobre 0 agendamento nas últimas décadas. A dinâmica do processo de agendamento midiático imposto pelas mídias massivas adquire novos contornos no "complexo ecossistema comunicativo" de midiatização na sociedade contemporânea, marcada, entre outros aspectos, pela multiplicação e diversificação de audiências conectadas (OROZCO-GÓMEZ, 2006). Em especial, as apropriações das redes sociais on-line são marcadas pela complementação e coexistência com meios massivos. Assim, a capacidade de selecionar as informações sobre as quais o público se volta é compartilhada entre as mídias, ou seja, uma mídia vai agendando outras mídias.

McCombs (2009), ao rever a teoria da hipótese da agenda setting desenvolvida décadas atrás, incorpora aos estudos as novas perspectivas produzidas pelo espaço on-line e a contribuição que este cenário pode trazer na ampliação das vozes. Um novo conceito - agendamento intermediático - revela a ênfase dada à integração e complementariedade das mídias na atualidade. Embora McCombs (2009) não detalhe ou conceitue precisamente a noção de agendamento intermidiático, podemos delimitá-la ao explorarmos o termo "intermidia". 0 conceito de intermidialidade, explica-nos Herkman (2012, p. 374, tradução nossa), tem origem nas teorias e movimentos artísticos dos anos 1960 e atémse "à continuidade dos formatos midiáticos e na articulação e rearticulação da mídia nos contextos sociais e culturais em transformação". A intermidialidade, explica, "enfatiza a análise da continuidade e da mudança nas mídias".

Com base em autores como Wenz (2008), que destaca a compatibilidade e a permeabilidade como características da intermidialidade, Alzamora e Tárcia (2012, p. 26) apontam que "a perspectiva intermidiática, nessa linha de raciocínio, deve se referir a formas de produção e circulação de informações que se estabelecem no cruzamento e complementaridade de ambientes midiáticos variados". Já Wenz (2008, p. 258) indica que "a intermídia produzida pelas novas 
mídias significa a integração ente mídias, 0 desenvolvimento de híbridos midiáticos e de novos sistemas de integração entre mídias".

Pensar um agendamento intermidiático, portanto, significa reconhecer e explorar as influências mútuas exercidas pelas diferentes mídias contemporâneas e pelas audiências a elas conectadas no sentido de negociar - reforçando, ampliando ou minimizando - a presença de um determinado assunto entre os destaques jornalísticos e em outras instâncias sociais. Essa perspectiva dialoga, por exemplo, com o que Primo (2008, p. 8) denomina "encadeamento midiático", para quem "já não se pode supor uma relação mutuamente excludente entre os níveis midiáticos. Pelo contrário, um nível recorre ao outro para se pautar, expandir sua atuação e até mesmo inspirar relatos e críticas a serem vinculados".

Uma das discussões proeminentes nesse contexto diz respeito ao efeito das crescentes relações intermidiáticas sobre 0 agendamento: a tendência seria uma fragmentação dos assuntos em destaques nos ambientes midiáticos ou um fortalecimento do poder de agendamento típico da lógica massiva de transmissão de informações? Conforme McCombs (2009, p. 224), alguns observadores preveem 0 fim do agendamento "à medida que as audiências se fragmentam e virtualmente todo mundo tem uma agenda midiática única que é um composto altamente especializado construído desta vasta riqueza de notícias e de fontes de informação". Para Pereira Neto (2011), essas previsões baseiam-se na pouca coesão das agendas da mídia e na formação de agendas pessoais diante da diversidade de conteúdos disponíveis para o público.

Nesse sentido, McCombs (2009, p. 223-224) afirma que "não há dúvida que a internet já expandiu muito a variedade de fontes de notícia e informação sobre temas públicos e sobre qualquer outro tópico que você imaginar", mas considera que há poucas evidências de que as novas tecnologias e a consequente segmentação das fontes de informação tenham sido capazes de fragmentar a audiência a ponto de criar diferentes agendas midiáticas. 0 papel cumprido pela "mídia noticiosa de elite" ao desencadear amplas coberturas de novos tópicos e a grande influência de "jornalistas-chave" na definição dos enquadramentos dados às notícias são, segundo 0 autor, exemplos da influência atual das mídias massivas no agendamento intermídia. Por outro lado, aponta McCombs (2009), identifica-se uma crescente importância da audiência conectada, contribuindo para uma "permeabilidade" da agenda de mídia.

\subsection{Agendamento em campanhas eleitorais}

As reflexões iniciais da hipótese da agenda setting, como já destacamos, foram desenvolvidas a partir de pesquisas realizadas durante campanhas eleitorais, o que reforça a pertinência dessas ocasiões para essa perspectiva teoricometodológica. Para McCombs (2009), "as eleições oferecem um ambiente dinâmico para se examinar 
tanto a influência das fontes noticiosas na mídia como, por sua vez, a influência da mídia no público" (McCOMBS, 2009, p. 171). Entre outras singularidades, as campanhas eleitorais são momentos em que os candidatos estão mais vulneráveis à exposição dos meios de comunicação e da população e também os eleitores estão potencialmente mais envolvidos e mobilizados para um debate público.

Fator determinante para o sucesso nas urnas, os políticos planejam suas campanhas eleitorais com a intenção de capturar a atenção da mídia. A cobertura noticiosa das atividades e dos assuntos referentes à campanha coloca 0 candidato na "agenda" dos meios de comunicação. Assim, as atividades atividades públicas dos candidatos tornam-se acontecimentos que pautam a mídia e, consequentemente, influenciam no agendamento do público (McCOMBS, 2009, p. 161).

\section{0 cenário comunicacional contemporâneo}

- marcado pela diversificação dos meios de comunicação e pela crescente relação intermidiática entre eles - amplia e modifica a relação entre política, mídia e eleitores e trazem novos caminhos para as campanhas eleitorais. Marques e Sampaio (2011) apontam duas características no atual modelo de circulação de informações políticas e eleitorais: "existe uma maior disponibilidade de informações geradas por candidatos, partidos e usuários; e, há consequentemente, uma maior concorrência pela atenção dos usuários" (MARQUES; SAMPAIO, 2011, p. 211).
Nesse contexto, agentes políticos passam a apropriar-se da internet no sentido de orientar 0 eleitor, pautar as instituições midiáticas e direcionar as coberturas jornalísticas a partir de critérios próprios de noticiabilidade. As ferramentas da internet representam uma oportunidade de expansão da base eleitoral de um político e um poderoso espaço de divulgação e disseminação de notícias. Utilizar os recursos digitais como instrumento de apoio para uma campanha torna-se fator estratégico, pois, "para agremiações políticas e candidatos, existe a possibilidade de se formarem novas redes de contato, de alcançar audiências particulares, de padronizar mensagens e, logicamente, de adotar estratégias organizacionais internas mais eficazes" (MARQUES; SILVA; MATOS, 2011, p. 348).

Considerando as características do ambiente digital, Cervi e Vieira (2010, p. 4) analisam 0 modelo descentralizado de produção permitido pelas redes sociais on-line destacando a "capacidade democratizante dessas ferramentas, o que significa pensar em como elas permitem uma pluralização do debate - seja modificando as rotinas produtivas dos jornalistas ou pela intervenção direta na esfera pública eletrônica". No caso da ferramenta de microblog Twitter, Marques e Sampaio (2011, p. 213) destacam como um dos maiores potenciais da ferramenta justamente esse "seu efeito de repercussão" através de recursos como hashtags e Trending Topics. Além disso, destacam Cervi e Mussuchin (2011, p. 6), “[...] os seguidores dos candidatos atuam como mediadores, repassando as 
informações aos demais eleitores ou interagindo com fontes tradicionais de informação". Trata-se de um "efeito cascata", com aponta Labella (2012) em uma análise da eleição espanhola de 2011.

A realização de campanhas eleitorais no atual ecossistema midiático aponta para a efetivação de um processo de agendamento intermidiático marcado por intensas relações dos diferentes atores envolvidos na produção e disseminação de informações. As potenciais apropriações da internet, portanto, sugerem uma relativização do agendamento de caráter massivo. Por outro lado, como aponta Herkman (2012), as performances dos candidatos nos meios massivos ainda são essenciais para as campanhas políticas contemporâneas e importantes fontes de informação para a maioria dos eleitores. Para o autor, "jornais impressos e o noticiário e os debates na televisão são as mais importantes fontes de informação para a maioria dos eleitores. As perfomances dos candidatos nessas mídias são essenciais para o resultado das eleições" (HERKMAN, 2012, p. 380, tradução nossa).

\section{Metodologia e dados coletados}

Considerando o panorama teórico apresentado, 0 objetivo principal da pesquisa empírica resumida a seguir foi discutir 0 agendamento intermidiático entre as redes sociais dos candidatos à prefeitura de Belo Horizonte e Vitória e a cobertura dos webjornais regionais Em.com.br e Gazeta Online nas eleições municipais de 2012.
Para tanto, após mapearmos os canais oficiais dos candidatos nas redes sociais on-line e as páginas especiais para eleições desenvolvidas pelos webjornais, foi feita uma observação diária das postagens. 0 s dados foram coletados entre 13 de agosto e 07 de outubro para a eleição municipal de Belo Horizonte, e até o dia 28 de outubro para a cidade de Vitória, onde houve segundo turno. Após 0 mapeamento de todas as publicações nos perfis oficiais dos candidatos a prefeito nas redes sociais on-line e de todas as matérias produzidas pelos dois webjornais nos três meses de coleta de dados, procuramos, neste artigo, sintetizar as principais tendências e exemplificá-las mencionando matérias e tweets/posts considerados exemplares das situações identificadas.

\subsection{Belo Horizonte (MG)}

Sete candidatos disputaram a prefeitura da capital de Minas Gerais, mas apenas três criam contas oficiais no Twitter e cinco, fanpages no Facebook, conforme destacamos no Quadro 1.

0 cenário eleitoral na capital mineira foi polarizado entre os candidatos Marcio Lacerda (PSB), que tentava a reeleição, e Patrus Ananias (PT). Estes dois candidatos foram também os que mais apropriaram-se das redes sociais on-line durante a campanha, sendo portanto o foco dos dados aqui apresentados. Já 0 webjornal Em.com.br lançou o canal "Especial Eleições 2012", espaço que trouxe detalhes da disputa eleitoral de Belo Horizonte 
Quadro 1: Perfis dos candidatos à prefeitura de Belo Horizonte no Twitter e Facebook

\begin{tabular}{|c|c|c|}
\hline Candidato (partido) & Canal(is) no Twitter & Página no Facebook \\
\hline Marcio Lacerda (PSB) & @MarcioPrefeito e @Marcio40BH & Marcio Lacerda \\
\hline Patrus Ananias (PT) & @Patrus_Ananias e @VotePatrus13 & Patrus Ananias \\
\hline Vanessa Portugal (PSTU) & @Vanessa_pstu & Vanessa Portugal \\
\hline Alfredo Flister (PHS) & - & Alfredo Flister \\
\hline Tadeu Martins (PPS) & - & Tadeu Martins Soares \\
\hline
\end{tabular}

Fonte: elaboração dos autores.

através de matérias sobre candidatos à prefeitura da capital mineira.

Durante o monitoramento dos perfis oficiais dos candidatos nas redes sociais on-line e das matérias publicadas no Em.com.br, a situação mais recorrente foi a publicização de temas comuns pautados pelas ações de campanha. A agenda de visitas dos candidatos a espaços de Belo Horizonte e as declarações emitidas por eles nesses locais pautaram as redes sociais e 0 webjornal, o que aponta para uma redundância e, principalmente, para um agendamento significativo em tornos dos temas e ações propostos pelos comitês de campanha.

Um caso típico dessa relação das notícias da campanha com os temas publicados nas redes sociais e nas matérias do portal é a divulgação de um Pacto pela Juventude assinado por Marcio Lacerda e pelo seu candidato a vice-prefeito, Délio Malheiros, assumindo o compromisso de investir em políticas voltadas para os jovens. No dia 21 de agosto, 0 ato foi divulgado através do perfil @marcio40bh e foi pauta de uma matéria no Em.com.br.

As polêmicas e críticas mútuas envolvendo os dois candidatos foram assuntos recorrentes nas matérias do webjornal durante toda a campanha eleitoral. Em geral, as declarações e respostas emitidas pelos candidatos à imprensa durante seus eventos de campanha se tornaram o lead das matérias do Em.com.br. Nas redes sociais dos candidatos, porém, quase sempre esses ataques ou bate-bocas foram ignorados, o que sinaliza um esforço para trabalhar uma "agenda positiva". Em algumas raras situações nota-se 0 uso das redes sociais para criticar, provocar ou mesmo referenciar 0 adversário direto. Ao comentar uma declaração de Marcio Lacerda de que torcia para que a chuva atrapalhasse o comício com presença do ex-presidente Lula, o perfil oficial de Patrus publicou: "ouvi falar que tem gente fazendo a dança da chuva por aí". 
Com o início da propaganda eleitoral gratuita observou-se um forte agendamento da TV em relação aos temas abordados pelo Em.com.br e pelas redes sociais dos candidatos. 0 webjornal destacou, já no primeiro dia (23 de setembro), os temas abordados nos programas exibidos no horário eleitoral gratuito dos candidatos a prefeito. A participação de apoiadores políticos de peso no horário eleitoral gratuito - Lula e Dilma no caso de Patrus e Aécio Neves e Antonio Anastasia no caso de Marcio Lacerda - também foi tema de matérias no Em.com.br e de postagens nas redes sociais dos candidatos.

Registramos alguns casos em que as matérias dos portais foram pautadas pelas mídias sociais. Um exemplo é uma matéria do webjornal que repercutiu um vídeo publicado pelo expresidente Luiz Inácio Lula da Silva em sua página no Facebook pedindo votos para os candidatos de seu partido, entre os quais Patrus Ananias. Já na reta final da campanha, as informações postadas nas mídias sociais adquiriram novas dimensões nos veículos jornalísticos, como na repercussão de um vídeo em que 0 candidato à vice da chapa do prefeito Marcio Lacerda, o deputado estadual Délio Malheiros (PV), aparece em uma entrevista gravada cinco dias antes do fechamento da chapa criticando a gestão do prefeito. 0 assunto foi destaque na imprensa e o Em.com.br divulgou matérias referentes ao tema, entre elas Vídeos de Malheiros faz Patrus e Lacerda se confrontarem, publicada dia 01 de outubro.
Outro vídeo que gerou polêmica na campanha mostrava a presidente Dilma Rousseff tecendo elogios a Marcio Lacerda e classificando o candidato adversário como "um dos melhores prefeitos deste país". Marcio Lacerda compartilhou na sua Fanpage um link do site YouTube e 0 webjornal repercutiu 0 assunto publicando a matéria Vídeos para atacar adversários são usados pelas campanhas de Lacerda e Patrus.

Por fim, em algumas poucas situações, as redes sociais dos candidatos referenciaram matérias publicadas por veículos jornalísticos. Especificamente o Em.com.br foi citado pelos perfis dos candidatos apenas na divulgação dos videochats promovidos pelo webjornal com os candidatos Marcio Lacerda e Patrus Ananias.

\subsection{Vitória (ES)}

Na capital do Espírito Santo, foram seis os candidatos à prefeitura da capital, dos quais cinco se apropriaram dos perfis no Twitter e de páginas no Facebook, conforme Quadro 2.

\section{Em comparação com Belo Horizonte, Vitória} apresentou uma disputa envolvendo mais candidatos com possibilidade de vencer nas urnas: Luiz Paulo Vellozo (PSDB), Luciano Rezende (PPS) e Iriny Lopes (PT) foram os nomes de maior peso na corrida pela prefeitura da capital. A eleição foi disputada, houve reviravolta nas pesquisas de intenção de votos e as eleições foram definidas apenas no segundo turno. 
Quadro 2: Perfis dos candidatos à prefeitura

de Vitória no Twitter e Facebook

\begin{tabular}{|c|c|c|}
\hline Candidato (partido) & Canal(is) no Twitter & Página no Facebook \\
\hline Luiz Paulo Vellozo (PSDB) & @LPVellozo & Luis Paulo Vellozo Lucas \\
\hline Luciano Rezende (PPS) & @LucianoRezende & Luciano Rezende \\
\hline Iriny Lopes (PT) & @iriny_13 & Iriny Lopes \\
\hline Gustavo de Biase (PSTU) & @GustavodeBiase & Edson Ribeiro \\
\hline Edson Ribeito (PSDC) & @edsonpsi & Giase 50 \\
\hline
\end{tabular}

Fonte: elaboração dos autores.

As características mais marcantes da divulgação das eleições via internet em Vitória foram 0 esvaziamento da cobertura da Gazeta Online e 0 uso intenso das redes sociais pelos principais candidatos à prefeitura, inclusive como promoção de eventos e ações on-line. 0 webjornal Gazeta Online criou uma página especial para cobertura das eleições, mas, ao contrário do Em.com.br em Belo Horizonte, não cobriu rotineiramente as ações de campanha dos candidatos. Durante vários dias do período eleitoral, não foi publicada uma matéria sequer pelo webjornal.

Por outro lado, em Vitória observou-se um trabalho intenso das equipes de campanha para promover ações via internet e integrar 0 eleitor ao projeto eleitoral do candidato. Um exemplo é 0 webcomício do tucano Luiz Paulo Vellozo Lucas, realizado semanalmente (às segundas-feiras, às 21h) com transmissão on-line através do site oficial do candidato. ${ }^{1}$ No seu perfil do Twitter, 0 candidato divulgou periodicamente o webcomício, convidando os eleitores a participarem e mandarem suas perguntas. Outro caso em que os candidatos apostaram nas potencialidades das mídias sociais foi o canal de integração "Pensar Vitória", ${ }^{2}$ um espaço da petista Iriny Lopes para discussão de propostas de governo. A candidata publicou regulamente no seu perfil do Twitter convites para que os eleitores participassem.

Um uso muito comum das redes sociais pelas assessorias dos candidatos a prefeito foi a divulgação de links de notícias publicadas pela Gazeta Online e por outros veículos jornalísticos. Este agendamento é exemplificado em uma publicação na página do candidato Gustavo De Biase (PSOL) no Facebook da 
reprodução de uma matéria do jornal A Gazeta que dava visibilidade a uma denúncia feita por De Biase contra 0 candidato Luciano Rezende. Após a imagem com a matéria, foi registrado no perfil "Gustavo De Biase 50" a seguinte frase: "Saiu hoje no Jornal A Gazeta: Precisamos de ética e independência na política! Não estamos a mando de ninguém". 0 candidato Luciano Rezende, envolvido no caso, não se pronunciou nas redes sociais sobre 0 assunto.

Em outras ocasiões, os candidatos disponibilizaram links de matérias do portal repercutindo temas da campanha e pesquisas de intenção de voto. Um caso que ilustra 0 agendamento das redes sociais pelo portal Gazeta Online é uma publicação do candidato Luiz Paulo Vellozo na sua fanpage que referencia matéria do webjornal publicada no dia anterior com 0 resultado da pesquisa de intenções de voto do Instituto Ibope mostrando 0 candidato tucano na liderança.

Tal como em BH, os programas eleitorais gratuitos exibidos na TV pautaram as matérias do portal capixaba. Por exemplo no dia 23 de outubro (durante 0 segundo turno), o portal Gazeta Online publicou uma matéria a respeito dos programas de reestreia dos candidatos na TV. De forma complementar, as propagandas eleitorais gratuitas na televisão pautaram as mídias sociais dos candidato, que divulgaram os vídeos e repercutiram os temas explorados em cada edição.
Nem sempre, no entanto, foi a TV quem desencadeou o processo de agendamento intermidiático. Um caso de grande repercussão nas redes sociais e nos jornais regionais e nacionais foi o do candidato Edson Ribeiro, que conseguiu chamar a atenção com um vídeo em que cheira a Bíblia com se estivesse inalando cocaína. Antes mesmo de ser veiculado no horário eleitoral gratuito na TV (no qual o candidato tinha apenas 1'40"), o vídeo foi ao ar na internet e alcançou visibilidade nas mídias sociais. Alimentando a polêmica, Edson Ribeiro postou no dia 13 de setembro um tweet em que diz: "não se preocupem povo de deus, todo ataque esta vindo de gente a mando do cheirador de cocaína". Veículos jornalísticos de todo país publicaram sobre o caso e, na sua página no Facebook, o candidato destacou essa repercussão nacional.

A grande movimentação das redes sociais na campanha eleitoral pela prefeitura de Vitória resultou em disputas e conflitos envolvendo perfis não oficiais e acabou tornando-se tema de algumas matérias produzidas pela Gazeta Online e por outros veículos jornalísticos. Na matéria Campanha entra na fase de Guerra Virtual, foram discutidas as páginas falsas na internet que debochavam e ironizavam os candidatos à disputa pela prefeitura de Vitória. Os perfis falsos voltaram a ser citados em matérias do portal publicadas no dia 30 de agosto, descrevendo que o perfil falso no Facebook "Uriny Lópolis" sairá do ar por determinação judicial. 


\section{Análise comparativa e considerações finais}

A partir dos dados sintetizados acima, podemos identificar diferenças significativas no processo de agendamento intermidiático entre as redes sociais on-line dos candidatos e a cobertura dos principais webjornais das duas cidades. Em Belo Horizonte, chama a atenção um grande alinhamento entre os temas divulgados pelos perfis oficiais e pelo Em.com.br e a agenda de campanha dos dois principais candidatos. No caso do webjornal, foram exploradas também as críticas aos adversários feitas durante esses eventos de campanha, algo que ocorreu raramente através dos perfis oficiais na reta final.

Também foram escassas as referências das redes sociais às matérias publicadas pelo Em.com.br ou outros veículos jornalísticos. Esse webjornal, por sua vez, raramente citou as redes sociais em sua cobertura e, quando o fez, foi para repercutir situações desencadeadas por fora dos perfis oficiais de campanha.

Em Vitória, acreditamos ser possível associar o esvaziamento da cobertura político-eleitoral da versão on-line do maior jornal do Espírito Santo com uma maior intensidade no uso das redes sociais oficiais para divulgação e debates de informações relativas à campanha. Como descrevemos, a promoção e divulgação de ações on-line (como "webcomícios") e a referência a matérias produzidas e ações promovidas pela
Gazeta Online foram algumas das apropriações mais comuns do Twitter e do Facebook pelas assessorias dos candidatos. Ao contrário do que ocorreu em Belo Horizonte, na cobertura da Gazeta Online foram recorrentes as referências a acontecimentos de campanha ocorridos na internet, principalmente daquilo que o próprio webjornal denominou "guerra virtual".

Nesse sentido, parece-nos claro que, na capital capixaba, desenrolou-se um intenso processo de agendamento intermidiático entre as redes sociais dos candidatos e a cobertura do webjornal Gazeta Online, enquanto em Belo Horizonte a única aproximação temática efetiva entre os perfis oficiais e 0 Em.com.br foi a cobertura comum dos eventos de campanha dos dois principais candidatos. Em ambas as capitais, no entanto, parece clara a forte influência exercida sobre a campanha eleitoral gratuita exibida na TV sobre as temáticas abordadas nas redes sociais e pelos webjornais de referência. Dessa forma, é importante apontarmos que, a despeito da crescente complexificação do ecossistema midiático contemporâneo, a transmissão televisiva - ao menos no que tange à cobertura $\mathrm{e}$ às repercussões eleitorais nas duas situações aqui estudadas - continua ocupando um espaço central.

Em pesquisas futuras, portanto, sugerimos que sejam observadas de forma mais sistematizada 0 agendamento intermidiático entre as mídias massivas (TV, em especial) e a cobertura/discussões na internet. No mesmo sentido, é fundamental considerar o impacto de perfis não oficiais nas redes 
sociais na campanha eleitoral. Além disso, parecenos relevante que a dinâmica de agendamento em outras capitais de mesmo porte seja analisada, o que propiciará novas comparações e discussões.

\section{Referências}

ALZAMORA. Geane; TÁRCIA, Lorena. A narrativa jornalística transmidiática: considerações sobre o prefixo trans. In: LONGHI, Raquel; D’ANDRÉA, Carlos (Org.). Jornalismo convergente: reflexões e experiências. Florianópolis: Insular, 2012. p.15-32.

BARROS FILHO, Clóvis de. Ética na comunicação: da informação ao receptor. São Paulo: Moderna, 2001.

BRUM, Juliana de. A Hipótese da Agenda Setting: estudos e perspectivas. Razón y Palabra, Atizapán de Zaragora, México, n. 35, out./nov. 2003.

CERVI, Emerson MASSUCHIN, Michele. Novas mídias e eleições 2010: 0 uso do Twitter nas campanhas dos candidatos ao governo do Paraná. In: ENCONTRO DA COMPOLÍTICA, 4., 2011. Rio de Janeiro. Anais..., Rio de Janeiro: Universidade do Estado do Rio de Janeiro, 2011. Disponível em: < http://www.compolitica.org/ home/wp-content/uploads/2011/03/Emerson-UrizziCervi-e-Michele-Goulart-Massuchin.pdf>

CERVI, Emerson; VIEIRA, Josiany. 0 twitter como pauta no jornalismo político do Paraná. Lumina, Juiz de Fora, v. 4, p. 1-10, 2010.

HERKMAN, Juha. Convergence or intermediality? Finnish political communication in the New Media. Convergence: The International Journal of Research into New Media Technologies, v. 18, n. 4, p. 369-384, 2012.

LABELLA, Luis Izquierdo. Las redes socials en la política espanõla: Twitter en las elecciones de 2011.

Estudos em Comunicação, n. 11, p. 139-153, maio 2012.

MARQUES, Francisco Paulo Jamil Almeida; SAMPAIO, Rafael Cardoso. Internet e eleições 2010 no Brasil: rupturas e continuidadesnos padrões mediáticos das campanhas políticas online. Galáxia, São Paulo, n. 22, p. 208-221, dez. 2011.

MARQUES, Francisco Paulo Jamil Almeida; SILVA, Fernando Wisse Oliveira; MATOS, Nina Ribeiro.

Estratégias de comunicação política online: uma análise do perfil de José Serra no twitter. Contemporânea comunicação e cultura, v. 9, n. 3, set./dez. 2011.

MCCOMBS, Maxwell. A teoria da agenda: a mídia e a opinião pública. Petrópolis, RJ: Vozes, 2009.

MCCOMBS, Maxwell E.; SPELLMAN Charles; WEAVER, David. Watergate and the media: A case study of Agenda-setting. In: TRAQUINA, Nelson. 0 poder do jornalismo: análise e textos da teoria de agendamento. Coimbra: Minerva, 2000. p. 63-76.

MCCOMBS, Maxwell E.; SHAW, Donald L. A função do agendamento dos media. In: TRAQUINA, Nelson. 0 poder do jornalismo: análise e textos da teoria do agendamento. Coimbra: Minerva, 2000. p. 47-62.

OROZCO-GÓMEZ, Guillermo. Comunicação social e mudança tecnológica: um cenário de múltiplos desordenamentos. In: MORAES, Denis de (Org.). Sociedade midiatizada. Rio de Janeiro: Mauad, 2006.

PEREIRA NETO, Pedro. Definindo a agenda dos agendasetters: estratégias, oportunidades e constrangimentos ao agendamento mediático na era das Tecnologias da Informação e Comunicação. Observatório Journal, v. 5, n. 2, p. 241-269, 2011.

PRIMO, Alex. A cobertura e o debate público sobre os casos Madeleine e Isabella: encadeamentomidiático de blogs, Twitter e mídia massiva. Galáxia, São Paulo, v. 16, 2008.

TRAQUINA, Nelson. 0 poder do jornalismo: análise e textos da Teoria do Agendamento, Coimbra: Minerva, 2000.

WENZ, Karen. As formas intermidiáticas em textos digitais. In: SANTAELLA, Lúcia; NÖTH, Winfried (Org.).

Palavra e imagem nas mídias: um estudo intercultural. Belém: Editora Universitária UFPA, 2008. 
Intermedia agenda setting in 2012 brazilian municipal elections: relationships between social networking websites and regional news sites in two capitals

Intermedia agenda setting en elecciones municipales de Brasil en 2012: relaciones entre las redes sociales y webjornais regionales en dos capitales

\section{Abstract}

This paper aims to discuss the intermedia agenda setting between social networks of the candidates for mayor of Belo Horizonte and Vitória and coverage of regional news sites Em.com.br and Gazeta Online in 2012 (regional news sites) brazilian municipal elections. We present a discussion on the origins and evolution of the reflections and research on agenda setting and, then, we focus on its ocorrency in contemporary election campaigns. After a systematic observation of the material published by the two websites and official profiles of the candidates, we present the main trends of intermedia agenda setting in the campaigns of the two capitals. The analysis highlighted significant differences: in Victoria we noticed a strong intermedia agenda setting between social networks and news sites while in Belo Horizonte there's a alignment with the campaign agenda of the two main candidates.

\section{Keywords}

Intermedia agenda setting. Elections. News sites. Social Networking.

\section{Resumen}

$\mathrm{El}$ artículo tiene como objetivo discutir la intermidia agenda setting entre las redes sociales de los candidatos a lo gobierno municipal de Belo Horizonte y Vitória y la cobertura regional de sitios de noticias Em.com.br e Gazeta Online en las elecciones municipales de 2012 in Brasil. Hemos iniciado un debate acerca de los orígenes y evolución de la reflexión y la investigación sobre la agenda setting e nos dirigimos a su aplicacion en las campañas electorales contemporáneas. Después de una observación sistemática del material publicado por los dos sitios de noticias y los perfiles de los candidatos, se presentan las principales tendencias de la intermidia agenda setting en las campañas de las dos capitales brasileñas. En el análisis, se destacan diferencias significativas: en Victoria nota una fuerte intermidia agenda setting entre las redes sociales y sitios de noticias mientras que en Belo Horizonte existe una alineación con el calendario de campaña de los dos candidatos principales.

\section{Palabras-Clave}

Intermedia agenda setting. Elecciones. Sitios de noticias. Redes Sociales. 


\section{Expediente}

A revista E-Compós é a publicação científica em formato eletrônico da Associação Nacional dos Programas de Pós-Graduação em Comunicação (Compós). Lançada em 2004, tem como principal finalidade difundir a produção acadêmica de pesquisadores da área de Comunicação, inseridos em instituições do Brasil e do exterior.

\section{E-COMPÓS I www.e-compos.org.br I E-ISSN 1808-2599}

Revista da Associação Nacional dos Programas

de Pós-Graduação em Comunicacão.

Brasília, v.16, n.2, maio/ago. 2013

A identificação das edições, a partir de 2008

passa a ser volume anual com três números.

\section{CONSELHO EDITORIAL}

Afonso Albuquerque, Universidade Federal Fluminense, Brasil Alberto Carlos Augusto Klein, Universidade Estadual de Londrina, Brasil Alex Fernando Teixeira Primo, Universidade Federal do Rio Grande do Sul, Brasil Ana Carolina Damboriarena Escosteguy, Pontifícia Universidade Católica do Rio Grande do Sul, Brasi

Ana Gruszynski, Universidade Federal do Rio Grande do Sul, Brasil Ana Silvia Lopes Davi Médola, Universidade Estadual Paulista, Brasil André Luiz Martins Lemos, Universidade Federal da Bahia, Brasil Ângela Freire Prysthon, Universidade Federal de Pernambuco, Brasil Antônio Fausto Neto, Universidade do Vale do Rio dos Sinos, Brasil Antonio Carlos Hohlfeldt, Pontifícia Universidade Católica do Rio Grande do Sul, Brasil Antonio Roberto Chiachiri Filho, Faculdade Cásper Líbero, Brasil Arlindo Ribeiro Machado, Universidade de São Paulo, Brasil Arthur Autran Franco de Sá Neto, Universidade Federal de São Carlos, Brasil Benjamim Picado, Universidade Federal Fluminense, Brasil

César Geraldo Guimarães, Universidade Federal de Minas Gerais, Brasil Cristiane Freitas Gutfreind, Pontifícia Universidade Católica do Rio Grande do Sul, Brasil Denilson Lopes, Universidade Federal do Rio de Janeiro, Brasi Denize Correa Araujo, Universidade Tuiuti do Paraná, Brasil Edilson Cazeloto, Universidade Paulista , Brasi Eduardo Peñuela Cañizal, Universidade Paulista, Brasil Eduardo Vicente, Universidade de São Paulo, Brasil Eneus Trindade, Universidade de São Paulo, Brasi Erick Felinto de Oliveira, Universidade do Estado do Rio de Janeiro, Brasi Florence Dravet, Universidade Católica de Brasilia, Brasil Francisco Eduardo Menezes Martins, Universidade Tuiuti do Paraná, Brasil Gelson Santana, Universidade Anhembi/Morumbi, Brasil Gilson Vieira Monteiro, Universidade Federal do Amazonas, Brasil Gislene da Silva, Universidade Federal de Santa Catarina, Brasil Guillermo Orozco Gómez, Universidad de Guadalajara

Gustavo Daudt Fischer, Universidade do Vale do Rio dos Sinos, Brasil Hector Ospina, Universidad de Manizales, Colômbia

Herom Vargas, Universidade Municipal de São Caetano do Sul, Brasi leda Tucherman, Universidade Federal do Rio de Janeiro, Brasil Inês Vitorino, Universidade Federal do Ceará, Brasil Janice Caiafa, Universidade Federal do Rio de Janeiro, Brasil Jay David Bolter, Georgia Institute of Technology Jeder Silveira Janotti Junior, Universidade Federal de Pernambuco, Brasil João Freire Filho, Universidade Federal do Rio de Janeiro, Brasil John DH Downing, University of Texas at Austin, Estados Unidos
José Afonso da Silva Junior, Universidade Federal de Pernambuco, Brasi José Carlos Rodrigues, Pontifícia Universidade Católica do Rio de Janeiro, Brasi José Luiz Aidar Prado, Pontifícia Universidade Católica de São Paulo, Brasil José Luiz Warren Jardim Gomes Braga, Universidade do Vale do Rio dos Sinos, Brasil Juremir Machado da Silva, Pontifícia Universidade Católica do Rio Grande do Sul, Brasil Laan Mendes Barros, Universidade Metodista de São Paulo, Brasil Lance Strate, Fordham University, USA, Estados Unidos Lorraine Leu, University of Bristol, Grã-Bretanha Lucia Leão, Pontifícia Universidade Católica de São Paulo, Brasil Luciana Panke, Universidade Federal do Paraná, Brasil Luiz Claudio Martino, Universidade de Brasília, Brasil Malena Segura Contrera, Universidade Paulista, Brasil Márcio de Vasconcellos Serelle, Pontifícia Universidade Católica de Minas Gerais, Brasil Maria Aparecida Baccega, Universidade de São Paulo e Escola Superior de Propaganda e Marketing, Brasil

Maria das Graças Pinto Coelho, Universidade Federal do Rio Grande do Norte, Brasil Maria Immacolata Vassallo de Lopes, Universidade de São Paulo, Brasil Maria Luiza Martins de Mendonça, Universidade Federal de Goiás, Brasi Mauro de Souza Ventura, Universidade Estadual Paulista, Brasil

Mauro Pereira Porto, Tulane University, Estados Unidos Nilda Aparecida Jacks, Universidade Federal do Rio Grande do Sul, Brasi Paulo Roberto Gibaldi Vaz, Universidade Federal do Rio de Janeiro, Brasi Potiguara Mendes Silveira Jr, Universidade Federal de Juiz de Fora, Brasi Renato Cordeiro Gomes, Pontifícia Universidade Católica do Rio de Janeiro, Brasil Robert K Logan, University of Toronto, Canadá

Ronaldo George Helal, Universidade do Estado do Rio de Janeiro, Brasil Rosana de Lima Soares, Universidade de São Paulo, Brasi Rose Melo Rocha, Escola Superior de Propaganda e Marketing, Brasil Rossana Reguillo, Instituto de Estudos Superiores do Ocidente, Mexico Rousiley Celi Moreira Maia, Universidade Federal de Minas Gerais, Brasi Sebastião Carlos de Morais Squirra, Universidade Metodista de São Paulo, Brasil Sebastião Guilherme Albano da Costa, Universidade Federal do Rio Grande do Norte, Brasil

Simone Maria Andrade Pereira de Sá, Universidade Federal Fluminense, Brasi Tiago Quiroga Fausto Neto, Universidade de Brasília, Brasil Suzete Venturelli, Universidade de Brasília, Brasil Valério Cruz Brittos, Universidade do Vale do Rio dos Sinos, Brasil Valerio Fuenzalida Fernández, Puc-Chile, Chile

Veneza Mayora Ronsini, Universidade Federal de Santa Maria, Brasi Vera Regina Veiga França, Universidade Federal de Minas Gerais, Brasil

\section{COMISSÃO EDITORIAL}

Adriana Braga I Pontifícia Universidade Católica do Rio de Janeiro, Brasi

Felipe Costa Trotta I Universidade Federal Fluminense, Brasi CONSULTORES AD HOC

Alexandre Barbalho, Universidade Estadual do Ceará, Brasil

Ana Carolina Escosteguy, Pontifícia Universidade Católica do Rio Grande do Sul, Brasi

Ana Gruszynski, Universidade Federal do Rio Grande do Sul, Brasi

Arthur Ituassu, Pontifícia Universidade Católica do Rio de Janeiro, Brasil

Claudia Lahni, Universidade Federal de Juiz de Fora, Brasil

Francisco Paulo Jamil Marques, Universidade Federal do Ceará, Brasil

Jiani Bonin, Universidade do Vale do Rio dos Sinos, Brasil

José Luiz Braga, Universidade do Vale do Rio dos Sinos, Brasil

Leonel Aguiar, Pontifícia Universidade Católica do Rio de Janeiro, Brasil

Luciana Panke, Universidade Federal do Paraná, Brasil

Marcelo Kischinhevsky, Universidade do Estado do Rio de Janeiro, Brasil

Raquel Paiva, Universidade Federal do Rio de Janeiro, Brasil

Sandra Rubia da Silva, Universidade Federal de Santa Maria, Brasil

EDIČ̃̃ DE TEXTO E RESUMOS I Susane Barros

SECRETÁRIA EXECUTIVA I Juliana Depiné

EDITORAÇ̃̃o ELETRÔNICA I Roka Estúdio

TRADUÇÃO I Sieni Campos
COMPós I www.compos.org.br

Associação Nacional dos Programas de Pós-Graduação em Comunicação

Presidente

Eduardo Morettin

Universidade de São Paulo, Brasil

eduardomorettin@usp.br

Vice-presidente

Inês Vitorino

Universidade Federal do Ceará, Brasil

ines@ufc.br

Secretária-Geral

Gislene da Silva

Universidade Federal de Santa Catarina, Brasil

gislenedasilva@gmail.com 